\title{
Employment, Education and the State
}

No. 188

15-Feb-2017

Sudipto Mundle

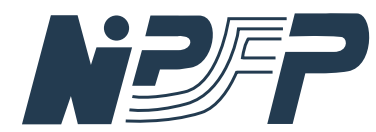

National Institute of Public Finance and Policy New Delhi 


\title{
Employment, Education and the State
}

\author{
Sudipto Mundle ${ }^{\#}$
}

\begin{abstract}
The 2016 India Employment Report demolishes the myths of both 'demographic dividend' and 'jobless growth' in the India growth story. But it recognises that the growth of decent, productive employment is too slow even to absorb the annual increment of new workers in the workforce, let alone eliminate the huge backlog of open unemployment and low productivity underemployment. This paper argues that this challenge is a man-made problem, the consequence of a range of dysfunctional policies that have a strong anti-employment bias. Moreover, a long standing elitist bias in education policy has pre-empted the provision of quality basic education without which the bulk of the workforce cannot be suitably skilled for decent, productive employment. The paper suggests that these dysfunctional policies are attributable to a fractionalized polity and India's soft state, which stands in sharp contrast to the hard states seen in the dramatically successful East Asian model of guided capitalism.
\end{abstract}

Keywords: Growth, employment, unemployment, underemployment, education, skill, productivity, dysfunctional policies, soft state, hard state, India, East Asia, guided capitalism

JEL Classification codes: O20,O43,O53, O25, P16,P47, P52, I25, I28, J08, J21

\footnotetext{
${ }^{*}$ This is a revised version of the Radha Kamal Mukherjee Memorial Lecture delivered at the 58th Annual Conference of the Indian Society of Labour Economics, Guwahati 24 November 2016. I am grateful to Ajit Ghosh, Pranab Bardhan, Shankar Acharya and Vijay Joshi for their comments on an earlier draft.All views expressed in the paper are solely of the author.

${ }^{*}$ Dr. Sudipto Mundle is Emeritus Professor, NIPFP.
} 


\section{INTRODUCTION}

Freedom fighter, philosopher, sociologist, economist, Radha Kamal Mukherjee was a man of many parts. He was also one of the pillars of the Indian Society of Labour Economics in its formative years. It is a great honour, and a humbling experience, to have been invited to give the lecture in his memory at the 58th annual conference of the Society. I would like to thank the Society and the Conference President, Dr. Ajit Ghosh, for giving me the opportunity to speak on the subject of workers and their employment conditions, a subject very close to Professor Mukherjee's heart.

Two great challenges face the Indian economy, the challenge of employment and the challenge of the environment. Here, I shall focus on the former. I will present some evidence of how the employment situation has improved during the 21st century. But I will also underline the formidable employment challenge that lies ahead. I will relate this to our multiple policy failures, especially in education, and India's soft state.

\section{THE CHALLENGE OF EMPLOYMENT}

Let me start with some sobering statistics. Without getting into the arcane debate around the choice of a poverty line, those living in India know quite well that a family of five, the average household size, would not be able to survive on an income of INR 10,000 per month, i.e., less than INR 67 rupees per head per day. On an income of up to INR 20,000 per month, or INR 133 per head per day, such a family might just about manage to make ends meet. But the slightest negative shock, an illness, temporary loss of job, etc., would push it beyond the brink. For a family of five, INR 50,000 per month or INR 333 per head per day, may be considered the minimum they would need to live a decent life.

I use these benchmarks because the Labour Bureau's recently released Fifth Annual Employment-Unemployment Survey Report, henceforth LBS 2016 (Labour Bureau, 2016) tells us that in 201516 about $85 \%$ of India's workers earned less than or up to INR 10,000 a month. Only $0.5 \%$ of workers earned INR 50,000 or more. About 54\% of the households surveyed had only one earning member, and another $31 \%$ had only two earning members. Thus, arguably, the majority of our worker households still live at the margin of survival on INR 20,000 per month or less. A negligible one percent or less of working households are able to earn a decent living of INR 50,000 per month or more.

Thus, the vast majority of India's working households are still living precariously on the brink of survival. Will it be possible within the next decade or so to create enough productive jobs so that this huge workforce can earn a decent living? That is the challenge of employment.

India's highly segmented labour market, the many shades of employment, underemployment, and unemployment imply that little meaning can be attached to the total level of employment or the rate of unemployment. Fortunately, we have two independent but similar sources of data that are designed to capture the complexity of the employment picture in this country. One source is the biennial LBS cited 
earlier. The other is the long established quinquennial Survey of Employment and Unemployment of the National Sample Survey Organisation (NSSO). Despite differences in sample design, methodology and some conceptual categories, the employment structure and trends derived from these two sources are quite similar.

Drawing mainly on the unit level data from the 55th and 68th rounds of the NSSO surveys, supplemented by data from the Annual Survey of Industries, Dr. Ajit Ghosh has skilfully demolished several myths and misconceptions about the unemployment situation in India in the recently published India Employment Report of the Institute of Human Development, henceforth IER 2016 (Ghosh, 2016).

\subsection{The Myth of Jobless growth}

Based on the Usual Principal Status concept, those who had work for more than half the reference year, the LBS estimates that employment remained virtually static at 438 million persons in 201314 and 440 million in 2015-16. During this period total population above the age of 15, the LBS concept of working age, grew from 878 million persons to 920 million persons. A similar picture of very sluggish employment growth appears using recent rounds of the NSS Employment Unemployment surveys. This has led to a widely held belief that growth in India has been virtually jobless.

However, this impression of static employment is quite misleading as Ghosh has pointed out in IER 2016. In the absence of social security, poor households cannot afford to remain completely unemployed. If proper jobs are not available, they will take on any work that is available, casual, informal, part-time - anything to survive. Thus, an aggregate figure of employment is typically much larger than the actual level of regular, productive employment, and does not give us an adequate picture the actual condition of the labour market. Ghosh explains that when conditions improve and household income rises, those at the bottom layer may simply withdraw from the labour market. Those remaining in the market move up the hierarchy to better quality jobs.

There is a job quality hierarchy in the highly segmented Indian labour market. First, there is the organised sector, with regular formal employment in this sector being the best quality of job. It is contractual, with full protection of labour rights, high wages and perks. This is followed by regular but informal employment in the organised sector, without full contractual protection of labour rights and lower wages. Then comes casual employment in the organised sector, with higher underemployment or fewer days of actual available work per worker. Next there is regular but informal employment in the unorganised sector, followed by casual employment in the unorganised sector, and finally self employment. This institutional structure can be further disaggregated into sectors of production, e.g., agriculture, industry, services and so on.

In this complex, segmented, labour market an assessment of trends in employment-unemployment has to be gleaned from the changing structure of employment, along with trends in real wage rates, not just the aggregate employment estimate. For this purpose, Ghosh has graded the quality of employment in each segment of the labour market and constructed an Employment Structure Index that rises when job conditions improve and workers shift to better quality jobs or to better market segments.

Comparing the NSS surveys of 1999-2000 and 2011-12, IER 2016 assesses that employment conditions have improved significantly during the twenty-first century. Employment in the organised sector has grown aggressively, faster than in the unorganised sector, with a fairly high growth elasticity of 
employment of 0.7. Workers have moved to better quality jobs: from informal to formal, casual to regular, and from the unorganised sector to the organized sector. Accordingly, the Employment Structure Index has risen. Real wages have also risen for virtually all categories of work. Underemployment has decreased, hence income per worker has risen even faster than real wages, lowering poverty incidence across the board. Productivity has also risen in all sectors, but faster in the unorganized sector than in the organized sector. Hence, dualism - the differences in productivity and real wages between the organised and unorganised sectors, has declined.

This assessment of the improving structure of employment and conditions of employment requires us to revisit the jobless growth debate from a different perspective. However, IER 2016 does not offer much ground for jubilation on that score. It points out that the organised sector still accounts for only 17 per cent of total employment. Regular formal employment in the organised sector, the best quality jobs, account for only 9 per cent. Self employment, and casual wage employment, the bottom layers of the labour market, still account for 78 per cent of total employment. Low productivity employment in agriculture still accounts for 43 per cent of total employment, and the incidence of underemployment is still very high; so is, the incidence of poverty. India still accounts for the largest number of the world's poor in absolute numbers.

Moreover, it is quite likely that the improvement reported in the IER has not been sustained beyond 2011-12. The IER covers the period up to 2011-12 based on NSS surveys, but the latest LBS 2016 report enables us to extend the assessment up to 2015-16. The LBS data are not comparable with the IER, especially because the former does not distinguish between the organised and unorganised sectors. However, it is possible to construct a modified Employment Structure Index for the four categories of workers in the LBS surveys: regular wage/salary workers, self-employed workers, contract workers and casual workers. Such an index shows a small decline in the modified Employment Structure Index from 2.52 in $2013-14$ to 2.48 in $2015-16$.

\subsection{The Myth of Demographic Dividend}

I mentioned earlier that the LBS estimate of total number of employed persons had changed very little between 2013-14 and 2015-16. During the same period, the LBS estimate of unemployment remained fixed at 23 million persons, and the size of the labour force, those available for work, also remained more or less static, increasing merely from 461 million in 2013-14 to 463 million in 2015-16. The corresponding projection in the IER, based on data up to 2011-12, would work out to about 471 million persons after excluding child labour - a small difference compared to the LBS estimate.

The slow growth of the labour force is mainly attributable to a decline in the labour force participation rate (LFPR), though population growth has also slowed down during this period. Comparing NSS surveys for 1983, 1999-2000 and 2011-12, IER 2016 has pointed out that there is a sustained decline in LFPR across age groups. What accounts for this? While there has been some reduction in LFPR among children and the elderly, by far the most important explanation is the decline in the LFPR for the working age group 15-60, especially among women.

The IER argues that this decline is mainly on account of declining poverty. It points out that women's LFPR declined the most among the poorest households, whereas, it actually increased in the case of better-off households. Similarly, by levels of education, women's LFPR declined among those not literate or the least educated, but increased among those with higher levels of education. The interpreta- 
tion is that women who were earlier forced to take on the worst paid, lowest quality jobs because of their poverty have withdrawn from those jobs as their household incomes have risen on account of better paid jobs for their husbands.

The decline in the LFPR demolishes the myth of a so called 'demographic dividend' that was supposed to come from the rising population share of the working age group, and a consequent decline in the dependency ratio. The share of the working age population has indeed been rising. But the share of the young who are actually in the work force has been declining as a consequence of the declining LFPR. Hence, the dependency ratio has been rising instead of falling. Alas, there will be no demographic dividend unless the decline of the LFPR is reversed or at least arrested ${ }^{1}$.

\subsection{The Employment Challenge}

It was stated at the outset that the vast majority of working people in India are still living precariously on the brink of survival, and that the challenge of employment is the question of whether or not it will be possible within the next decade or so to create enough productive jobs so that this huge workforce can earn a decent living.

This question can be put in a quantitative perspective. Staying with the IER projections, and excluding subsidiary, elderly and child workers, India has a core labour force of 433 million, of whom 22 per cent are women. The challenge of employment and unemployment essentially relates to this stock of about half-a-billion people. The stock is growing at 1.5 per cent per year, implying that on average there will be another 6 to 8 million young persons entering the labour force each year for the next decade or so. Employing this incremental labour force alone will require the level of employment, currently 420 million persons on UPS basis, to grow at an average annual rate of $1.7 \%$.

In addition there are around 13 million persons openly unemployed, 30 per cent of them women. Plus there are around 52 million persons, 65 per cent of them women, in 'disguised unemployment', such low productivity work that withdrawing them would make little difference to the level of output. Finally, there are another 52 million persons, all women, who are not in the labour force but would be available for work if there were adequate opportunities for productive employment according to Ghosh (2016). Thus, there is a backlog of 117 million persons, 78 per cent of them women, who need to be absorbed into new and more productive jobs.

Eliminating this backlog over, say, the next fifteen to twenty years would require another 6 to 8 million jobs to be added annually. Thus, to employ all new entrants to the labour force plus absorb the backlog over this period the required annual growth of employment would have to be well over 3 per cent. That is the scale of the employment challenge that India faces today.

\section{EMPLOYMENT AND DYSFUNCTIONAL POLICIES}

As compared to that required scale of job growth, the current trend of actual job growth has been much less. The LBS data for 2013-14 and 2015-16 indicates that there has been virtually no growth in

${ }^{1}$ However, a 'demographic dividend' of sorts may still arise from declining fertility leading to smaller family sizes and higher per capita incomes. 
employment during this period. Even if we take the IER estimate up to the year 2011-12, employment has grown at only $1.5 \%$ per year, implying a net addition to the backlog every year. Thus the structure of employment may be improving and workers are moving up the job segment hierarchy to better quality jobs. But the pace at which the organised sector is able to pull workers out of the unorganised sector is excruciatingly slow compared to need. As a consequence, only $20 \%$ of workers are employed at good salaries for high productivity jobs, and in decent working conditions, in the organised sector. Of these, again, about half are informally employed in the organised sector. The vast majority of workers, $80 \%$, are still crowded into the unorganised sector, in micro enterprises employing 9 or less workers at meagre wages for low productivity jobs, and mostly in very poor working conditions.

In agriculture almost the entire workforce is in the unorganised sector. Of some 17 million manufacturing enterprises over $99 \%$ are micro-enterprises of less than 10 employees which account for over $80 \%$ of workers in the sector. Small enterprises with 10 to 49 employees account for only an estimated $3 \%$ of the work force. Medium enterprises with 50 to 200 hundred employees account for another $6 \%$ of the workforce, and large enterprises with over 200 employees account for the balance $11 \%$ of the workforce. The size structure of employment in services is similar (Joshi 2016, World Bank 2011).

This remarkably skewed Indian size structure of enterprises and employment, with a missing middle segment of small and medium enterprises employing between 10 to 200 employees, unique among major Asian economies, has entailed a huge cost in lost productivity and low wages (Ghosh, 2016; Joshi, 2016; Acharya and Mehrotra, 2016). Productivity in agriculture sector is only one-fifth of the productivity in non-agricultural sector. Within non-agricultural sector, productivity in unorganised industry is only one-sixth that in organised industry while productivity in unorganised services is a third of that in unorganised services. Wages in the unorganised sector are also only a fraction of wages in the organised sector.

What accounts for the low growth of overall employment and the slow pace of transfer of workers from the unorganised to the organised sector? There are several factors at work here. But as a generic explanation, it can be argued that India's dire employment situation is a man-made problem, the result of a whole range of dysfunctional policies. As Vijay Joshi has argued in his recent book, India's Long Road to Prosperity (Joshi, 2016), these dysfunctional policies collectively add up to a strong anti-employment bias in the policy environment.

One of the early policies that directly restricted the growth of organised sector employment for decades was the policy of reservation of dozens of labour intensive industries for small enterprises and 'village and cottage industries'. These were almost by definition very low productivity enterprises, precluded from enjoying the vast potential for economies of scale in these industries. Though the reservation policy has gone, it has left its mark on the skewed structure of employment. Besides, a host of other policies remain which perpetuate the anti-employment bias of the policy regime.

Central to this anti-employment bias are the laws relating to labour. Critics usually point to the Industrial Disputes Act (IDA), as amended in 1982, which is applicable to all firms employing 100 workers or more. It requires all firms covered by it to secure approval of state governments before either closing down operations or laying off or dismissing any employee. Obviously such a rigid law is highly dysfunctional. It is a strong deterrent to entry and, for smaller firms with less than 100 workers, a deterrent to hiring more workers. 
However, the negative employment impact of this particular law is overstated in my view. It only applies to firms in the organised sector that are relatively large by Indian standards. As I have mentioned earlier, only 20 percent of the Indian work force is employed in the organised sector, and of that about half are contractual employees whose removal would not attract IDA provisions. In fact, if IDA was such an important constraint, we would expect to see a bunching of firms close to or just below the $100 \mathrm{em}$ ployee threshold. No such bunching is evident.

But IDA is not the only law relating to labour. The Contract Labour Act of 1970, applicable to all firms employing 20 persons or more, restricts the activities for which contract labour can be used. The Factories Act covers all firms employing 10 workers or more. This is the act which has the most negative impact in my view, because we see a massive bunching of firms below the 10 employee threshold. Joshi points out that out of 17 million enterprises in manufacturing that were recorded a few years ago, 99.3\% were micro-enterprises employing 9 or less workers.

Joshi also points out there are altogether 50 central laws and another 150 state laws relating to labour. Then there are implementation rules and a huge baggage of case laws relating to these laws. It is no wonder that enterprise owners balk at navigating their way through this Kafkaesque maze. There is substantial research evidence which demonstrates that states with more flexible labour laws also have a larger share of employment in organised sector firms and faster growth of larger, more labour employing firms (Besley and Burgess, 2004).

Staying below the employment threshold of labour laws is only one aspect of the preference of enterprises to stay below the regulatory radar screen (Hasan and Jandoc, 2013). Regulation covers everything from building permits, water and power supply to labour, taxation, pollution and transportation of goods. This omnipresent regulatory system is implemented by an army of predatory inspectors with discretionary powers. These powers are deployed as much for rent-seeking as for regulation. World Bank surveys of thousands of firms conducted a few years ago indicated that corruption, i.e., harassment and bribe seeking, was one of the leading constraints to their operation and growth (World Bank, 2011).

But a predatory regulatory environment is not the only constraint blocking the growth of enterprises. The same surveys identified lack of reliable power supply as another primary obstacle, with $40 \%$ of firms surveyed forced to their own power at high cost. Transportation is a constraint for enterprises in rural areas, as also the lack of access to credit. Land scarcity is an important constraint in urban areas. The state is not mandated to meet all these deficits. But it is mandated to adequately provide public goods, and to eliminate the massive distortions in the markets for power, land and credit that have led to the deficits in these markets.

The inevitable conclusion is that the slow growth of productive employment is a man-made phenomenon, the consequence of dysfunctional policies (Gupta, Kumar and Hasan, 2009).

\section{THE FAILURE OF EDUCATION POLICY}

However, even if by some miracle all the dysfunctional policies cited so far were to be reversed or eliminated overnight, the bulk of the Indian workforce would still remain trapped in low productivity, 
low paid jobs. The binding constraint on productive employment growth is the failure of another major policy, namely India's education policy. The education level of the large majority of Indian workers enables them to acquire only low or at best medium levels of skill. Just a small proportion have the educational foundation required for highly skilled, high productivity jobs in large enterprises in the organised sector. As of now, barely $5 \%$ of the workforce in India has had any skill training. Only $2 \%$ have any formal skill certificate compared to over $70 \%$ in advanced European countries like UK or Germany, and as much as $80 \%$ to $90 \%$ in East Asian countries like Japan and Korea (Ghosh, 2016; Joshi, 2016; Acharya and Mehrotra, 2016).

Recognising this huge deficit, and building on an initiative of the previous government, the present government introduced a National Skill Development and Entrepreneurship Policy in 2015 (Govt. of India, 2015). A well-conceived policy, it has launched various programmes, including the flagship Pradhan Mantri Kaushal Vikas Yojana (PMKVY), to train roughly 400 million workers in the 15-45 age group over the next seven years. This ambitious programme notwithstanding, the results are not very impressive. In its submission to a Parliamentary Committee earlier this year, the government indicated that of the 17.6 lakh candidates trained under PMKVY till 25 April, 2016, only 5.8 lakhs could be certified as having successfully completed the training, and less than 82,000 were actually placed in jobs (Magazine, 2016). Why is the success rate so low? The answer is quite simple. No skill development programme, however well designed, can succeed without an underlying foundation of basic education. But India's long standing neglect of primary and secondary education has greatly limited the access to quality basic education (Ghosh, 2016; Joshi, 2016 and Mundle, 2016).

The elitist bias of India's approach to education is evident not in the stated policies, but in the manner of their implementation and the outcomes (Agarwal, 2007). The demand for free and compulsory education was originally raised more than a hundred years ago in the 'Gokhale Bill' presented to the Legislative Council of colonial India in 1911 and finally passed in 1913 (Sikdar, 2016). After independence, the 1968 National Policy on Education (NPE) of 1968, based on the recommendations of the famous Kothari Commission, advocated free and compulsory education for all till age 14, and called for special attention to education of girls and children of deprived communities (Govt. of India, 1968). But these were inadequately funded mandates and the goals could not be achieved. The approach of NPE 1968 was followed by the new National Policy on Education of 1986 and most recently the Right to Education Act (RTE) of 2009 (Govt. of India 2009), which has made free and compulsory education a legal right for all children from age 6 to 16.

Unfortunately, the mandates are inadequately funded (Jha et al., 2015) and the policies have focussed on enrolment and inputs rather than outputs for which the government can be held accountable. Hence, after decades of lofty policy goals, the results have been underwhelming compared to some of our Asian neighbours and other emerging market economies. Thus, India is finally approaching the goal of universal primary education more than 100 years after the 'Gokhale Bill' and 70 years after Independence. China had achieved this goal by the 1970s. Korea achieved it even earlier by the 1960s and had more or less achieved universal secondary education by the 1970 s. As of 2012 over $26 \%$ of India's population was still illiterate compared to $5 \%$ in South Africa, $4 \%$ in China and only 2\% in Turkey. About $50 \%$ of India's population had only primary education or less, compared to $38 \%$ in China, $24 \%$ in South Africa, and only 20\% in Turkey (Acharya and Mehrotra, 2016).

Oddly, the $13 \%$ population of India with tertiary education at the upper end is quite comparable with 10\% in China, 14\% in South Africa, and 15\% in Turkey. This peculiar 'missing middle' structure of 
India's education profile, neglecting basic education and attaching priority to higher education, starkly captures the elitist bias in the implementation of India's education policy, Half the population is still crowded at the bottom, either illiterate or with only primary education. Meanwhile, a disproportionately large segment is also bunched at the upper end with tertiary education (Ghosh 2016).

Even these statistics, depressing as they are, do not fully reflect the depth of India's education policy failure. For that we have to look at learning outcomes. The latest Annual Survey of Education Report (ASER, 2016) reports learning outcomes that are shocking. About $52 \%$ of class 5 students could not read a simple text meant for class 2 students. Similarly about $50 \%$ of class 5 students could not do a simple subtraction meant for class 2 students. Moreover, learning outcomes have also shown no improvement over successive ASER surveys. Deficits in foundational reading and arithmetic skills are cumulative, leaving students grossly handicapped for further education.

In 2008, six thousand students from Odisha and Rajasthan participated in the well known global TIMMS test for mathematics and science. They were ranked 43rd and 47th out of 49 . Their average performance was 3 standard deviations below the OECD average. In 2009 students from Himachal Pradesh and Tamil Nadu, educationally two of India's best performing states, took the PISA test conducted by OECD. The two states were at the bottom, ranked 72nd and 73rd out of 74. The average standard of the Indian students was comparable to that of the bottom fifth percentile of OECD students (Joshi, 2016). The Indian authorities have been too ashamed to participate in subsequent PISA tests, that are allegedly western style tests not suitable for Indian students. But the top three positions in 2009 went to Singapore, South Korea and Japan, and Asian countries have continued to rank at the top in subsequent PISA tests (Mitra, 2016). So much for the Indian fig leaf.

Why has India's school education policy been so ineffective? Among many factors, I believe the following are the most important. First, education policy in India is focussed on inputs rather than learning outcomes, which is what matters. Second, education policy has a strong elitist bias in favor of higher education as opposed to primary or secondary education. To illustrate, among Asian countries the ratio of per student public expenditure in tertiary relative to primary education is less than 4 in Malaysia, 2 in Indonesia and 1 in Thailand and Korea. In India it is over 9. Finally, and most importantly, the incentive structure for government school teachers is highly distorted, virtually guaranteeing poor performance.

Thus, teacher salaries in government schools are high relative to average incomes. It is about the same as per capita GDP in China but about three times per capita GDP in India. Moreover, teachers are guaranteed life-time employment as public servants regardless of performance. As a consequence, they have no accountability to their clients, namely the students and their parents. The little accountability they have is to their higher authorities, namely the state education department bureaucracy and that too is minimal.

Teachers are rarely reprimanded for non-performance, let alone being fired. High absenteeism is routine, around $25 \%$ according to some surveys. Even when present in schools, teachers often engage in activities other than teaching. Less qualified contract teachers, who are paid much less, actually do a much better job than the permanent teachers. Also learning outcomes are better in private schools though the average teacher salaries and cost per student is less. Predictably, the student share of private schools is rising fast. It is already over a third of total students even though private schools have fees while government schools are free. 
The failure of India's education policy has far reaching consequences. Given the fragile foundation of basic education, the large majority of our workforce cannot be trained for high skill, high productivity jobs. So we come full circle, back to the challenge of employment. India needs to employ an additional 16 million persons every year, progressively pulling them out of low productivity, low wage jobs in the unorganized sector to better paid, higher productivity jobs in the organized sector. But the IER estimates that only 5 million of the incremental jobs could be for high skilled work, mostly for young new entrants to the workforce and those openly unemployed with tertiary education. Given the low education profile of the presently surplus workers, they would mostly have to be employed in low or medium skill jobs, but better paid in the organised sector than in the unorganised sector.

But neither is the demand for such workers growing fast enough, nor is the supply of such suitably skilled workers who can negotiate the traverse from the unorganized to the organized sector. A recent report celebrated the fact that the employability of Indians looking for jobs had gone up in the last four years from around $34 \%$ to over $40 \%$ (Confederation of Indian Industry, 2016). Ironically, it also implied that nearly $60 \%$ of those looking for jobs are unemployable.

\section{DYSFUNCTIONAL POLICIES AND THE SOFT STATE}

The paper has argued that the problem of unemployment and underemployment in India is a man-made problem. Dysfunctional regulatory policies have created a bias against employment growth. And our education policy has failed to provide the mass foundation of quality basic education without which the workforce cannot be skilled to undertake well paid, high productivity jobs. But if bad policies are the problem, it can be asked, why not prepare a menu of reforms to reverse these policies? That should solve the employment problem.

It would indeed not be difficult to write down such a menu of desired policy reforms. But policies do not drop like manna from heaven at the behest of some enlightened God. Policies emerge in specific political economic contexts. They reflect the character of the state and are usually the outcomes of bargaining and manoeuvring among competing interest groups. So, the interesting question to ask is why certain policies came to be what they are.

In addressing this question, the East Asian experience provides a useful perspective for assessing the Indian experience. Following the end of the Second World War and colonialism, there emerged along the Eastern Pacific rim several fast growing countries, led by developmental states that shared many similar characteristics, of course with individual variations. This enables us to identify what I call the East Asian model of guided capitalism which is quite different from the prescribed model of the so called 'Washington Consensus'. The model was seen first in Japan, then in South Korea, Taiwan, Hong Kong and Singapore, later in China and most recently in Vietnam. Malaysia, Thailand and Indonesia have also attempted to follow this model, but with limited success ${ }^{2}$.

Without digressing too much it is useful to cite just a few key features of this model which serve as a useful

2 There is now a vast literature on this subject. See, among others, Vogel (1991), World Bank (1993), Chang (1996, 2007), Bardhan (2010, 2016) and Mundle (2017). 
benchmark against which to contrast India's development experience: strong states, inclusive development strategies, and capable bureaucracies driven by performance based incentives.

A key feature of the East Asian model is a strong developmental state that has the capacity to impose its will on civil society and pursue its goal with determination. Usually, but not always, these states have been authoritarian and unfettered by the political competition of democratic political systems. In all these countries, except the city states, the old landed elites were swept away by land reforms or considerably disempowered by the disruption of war. There emerged a new elite committed to the mission of rapid industrialisation.

American aid and defence protection provided most of these countries the opportunity to focus on their mission. The extension of American protection, and their own urge to urgently industrialise, were both driven by a shared fear of the spread of Communism, which had established a strong foothold in the region. Ironically, China, the communist giant of the region, was also driven by fear to urgently industrialise. In this case it was the fear of American domination.

The institutional framework adopted for this goal was guided capitalism. China adopted this framework from the late 1980s and Vietnam after the introduction of Doi Moi in the 1990s. Private enterprise was actively nurtured by the state to grow and become globally competitive. The state led by coordinating collective action. Industrial policy identified and extended state support to industries considered strategically important, picking winners when required, and eventually exposing them to global competition when they achieved maturity. Most of these countries started with manufacturing labour intensive light consumer goods, drawing on their comparative advantage of cheap labour, and only later went on to heavy industries and high technology products like electronics. East Asia, especially China, became the manufacturing centre of the world.

The focus on basic education and skills training has been a key component of this strategy of development. The availability of an army of educated and skilled workers was essential for labour intensive growth. Free universal basic education and public health, combined with the early emphasis on land reform, made inclusion an essential feature of the East Asian model. Thus, exclusive political institutions have presided over economic institutions that are inclusive.

Another essential feature of this model is a competent and disciplined bureaucracy committed to service delivery. Mass education provided the necessary foundation for building such a bureaucracy. Filtering through highly competitive examinations at various stages of education and eventual selection into the bureaucracy has ensured that the best are selected. But subsequent career progression is linked to performance. While patronage networks exist, such patronage is also generally linked to good performance. This has ensured that the bureaucracy is not only competent but also committed to perform. Since the state plays a leading role in coordination and collective action, good governance and a well performing bureaucracy has been a critical factor for the success of this model.

In sharp contrast to East Asia, the political institutions in India have been inclusive. But as Pranab Bardhan(2010), Varshney(2013) and other scholars have pointed out, the plural and inclusive political institutions have also contributed to the emergence of a soft state characterised by collective action gridlock. The Indian state came into existence as a democratic republic at the end of a remarkable non-violent national movement in which almost all sections of society participated. Unlike in East Asia, the pre-existing elite were neither swept away nor disempowered. The landed and business elites have 
continued to exercise great influence over public policy. But they are not the only interests that have mattered. The Indian state has throughout had to navigate its way through a very fractionalized polity with conflicting interests of different regions, classes, religions and castes.

Securing political consensus among these many competing political interests for any collective action has been virtually impossible. At the same time a large share of the state's revenues have had to be frittered away in various transfers and unwarranted subsidies to accommodate the many competing special interests of this fractionalized polity. As a consequence, the state has remained under fiscal stress from very early days, struggling to find the resources required for expenditure on public goods and merit goods like education, health and infrastructure, its primary responsibilities.

One major act of relative autonomy, uncharacteristic of the soft state, was the establishment of a substantial public sector. These public enterprises were the main vehicles to implement India's heavy industries first strategy, giving the state control over the 'commanding heights' of the economy. This too was in contrast with most East Asian countries, other than pre-reform China and Vietnam. However, these enterprises have been treated like fiefdoms of the politicians in power and the bureaucrats, and never allowed to function as independent, commercially viable enterprises. It was explained earlier how, at the same time, a dysfunctional regulatory environment obstructed the growth of private enterprises. As a consequence, India continued to underperform for many decades after Independence while the countries of East Asia surged ahead at an astonishing pace.

A second major contrast between East Asia and India is the persistence of exclusive economic and social institutions and the lack of inclusive growth. Like the East Asian states, the Indian state also started out with strongly egalitarian ambitions, reflected in the Directive Principles of the Constitution. However, unlike in those countries, the soft Indian state was not able to commit to this egalitarian agenda. Land reform became the first casualty, undermined by the landed interests who remained influential in post-colonial India. We have also seen how a dysfunctional education policy, in particular the failure to produce high quality universal primary and secondary education, preempted the creation of a large well educated and skilled workforce. This undermined the second plank of the egalitarian agenda.

Thus, India's inclusive political institutions came to rest on economic and social institutions that were highly unequal, i.e., the unequal distribution of land and other assets, the entrenched social inequality of the caste system and unequal opportunities for upward mobility through education. While inclusive growth was the declared goal of the state, the growth that actually occurred was not inclusive at all. To compensate for this, the state has had to continuously depend on add-on programmes such as subsidised food through the PDS and 'make work' employment programmes like MGNREGA.

The third major contrast between the East Asian model and India is the bureaucracy. When the state plays a coordination and collective action role in development, the nature of the bureaucracy is important. As in East Asia, Indian bureaucrats are appointed after multiple stages of filtration through examinations during education, culminating in a recruitment examination. So, the persons appointed as civil servants are of very high quality. However, unlike in East Asia, their subsequent career progression is not driven by performance-based incentives.

Independent India perpetuated an administrative system inherited from the colonial government without much reform, and the culture of ruler and ruled has persisted. Bureaucrats see themselves as rulers and the people they are supposed to serve are seen as the ruled. This elitist self-image is 
reinforced by the lack of any accountability to the people they supposedly serve. Lifetime job security at high salaries, relative to per capita GDP, without accountability encourages non-performance Their only accountability is to the hierarchy of their administrative bosses and the political leaders in power. That accountability is measured in terms of loyalty to the bosses, not service to the people. As the earlier example of education illustrated, the inevitable casualty of this distorted incentive system is the quality and delivery of public services.

Many of these limitations have been recognised, even by the bureaucracy itself. Several committees and commissions have given detailed recommendations on administrative reforms. However, none of these recommendations have ever been implemented. New prime ministers have often spoken eloquently about the importance of civil service reform at the beginning of their terms, then quietly dropped this item from their agendas. It points to the power and relative autonomy of India's bureaucrats even vis-a-vis their political masters.

\section{A CONCLUDING REMARK}

The forgoing emphasises some dimensions in which the soft state in India compares unfavourably with the strong states of East Asia only to highlight the systemic or institutional factors underlying India's policy failures. However, this should in no way be taken to imply that India should emulate the East Asian model in its entirety. There are things to learn from the East Asian model. But there are other aspects that must be firmly rejected, especially authoritarianism and the lack of political freedoms.

Inclusive political institutions throw up collective action challenges. But they are also India's greatest strength. Political freedom is the key to peaceful rather than cathartic resolution of conflicts among competing interests. More importantly, political freedom allows for change in the structure of power. One example is the progressive shift in balance of power from the Union government to the states. A second is the rise of the Dalits as a political force. Hopefully, these political changes will lead to more inclusive policies, and accelerate the slow pace of employment growth and job quality improvement. 


\section{REFERENCES}

Acharya S. and S. Mehrotra. 2017. Planning for Human Development: Lessons from the East Asian Experience, Indian Journal of Human Development (Forthcoming).

Agarwal P. 2007. From Kothari Commission to Pitroda Commission, Economic and Political Weekly, 42(7): 554-557.

ASER. 2016. All India (Rural) Annual Status of Education Report Pratham, New Delhi.

Bardhan P. 2010. Awakening Giants- Feet of Clay: Assessing the Economic Rise of China and India, Princeton University Press, Princeton: USA.

, 2016. State and Development: Need for a Reassessment of the Current Literature, Journal of Economic Literature, 54(3): 1-31.

Besley T. and R. Burgess. 2004. Can Labour regulation Hinder Economic Performance: Evidence from India, Quarterly Journal of Economics, 119(1): 91-134.

Chang H. 1996. The Political Economy of Industrial Policy, Palgrave Macmillan: UK.

, 2007. The East Asian Development Experience: The Miracle, the Crisis, and the Future Zed

Books, USA.

Confederation of Indian Industry, 2016. India Skills Report 2017. Confederation of Indian Industry; New Delhi, India

Ghosh A. 2016. India Employment Report: Challenges and the Importance of Manufacturing Led Growth, Institute of Human Development and Oxford University Press: New Delhi.

Government of India. 1968. National Policy on Education Ministry of Education, Government of India: New Delhi.

2009. The Right of Children to Free and Compulsory Education Act (No.35 of 2009), Gazette of India, Thursday, August 27, 2009, Ministry of Law and Justice, Government of India: New Delhi.

, 2014. Report of the Fourth Annual Employment Unemployment Survey 2013-14, Volume1, Labour Bureau, Ministry of Labour, Government of India: Chandigarh.

, 2015. National Policy for Skill Development and Entrepreneurship 2015, Ministry of Skill Development and Entrepreneurship, Government of India: New Delhi.

, 2016. Report of the Fifth Annual Employment Unemployment Survey 2015-16, Volume1, Labour Bureau, Ministry of Labour, Govt. of India, Chandigarh. 
Gupta P, R. Hasan and U. Kumar. 2009. Big Reforms but Small Payoffs: Explaining the Weak Record of Growth of India Manufacturing, India Policy Forum 2008-9, Volume 5, Sage Publications: New Delhi.

Hasan R. and K. Jandoc. 2013. Labour Regulations and Firm Size Distribution in Indian Manufacturing, in (ed.) J. Bhagwati and A. Panagariya. Reforms and Economic Transition in India, Oxford University Press: New Delhi.

Jha P, G. Rani, S. Sikdar, P. Paranti. 2016. Shifting Terrain of Public Policy Discourse for Financing of School Education, in (ed.) P. Jha and P.G. Rani, Right to Education in India: Resources, Institutions and Public Policy, Routledge: New Delhi.

Joshi V. 2016. India's Long Road: The Search for Prosperity, Allen Lane Penguin Books: India.

Magazine A. 2016. Pradhan Mantri Kaushal Vikas Yojana: Renewed Push for Faster, Better Results, Indian Express, 18 October.

Mitra Sumit. 2015. India’s PISA Moment: Are we Turning into a Nation of Nitwits? The Quint, Opinion, July 2. Retrieved from: weblink: https:/www.thequint.com/opinion/2015/07/02/.

Mundle S. 2016. Our Failed Education Policy Needs Urgent Reform, Mint, 10 December. , 2017. Beyond Catch Up: Speculations about the Next Twenty Five, NIPFP WP 187.

Sikdar S. 2016. School Education in India: An Assessment of PublicProvisioning since the Early 1990s, Unpublished Ph. D dissertation submitted to Jawaharlal Nehru University.

Vogel E.F. 1991. Four Little Dragons: The Spread of Industrialisation in East Asia. Harvard University Press: Cambridge, Mass., U.S.A.

World Bank. 1993. The East Asian Miracle: Economic Growth and Public Policy, Oxford University Press, Oxford and the World Bank: Washington.

, 2011. More and Better Jobs in South Asia, World Bank Publications: Washington. 
MORE BY THE AUTHORS

- Mundle, S., Chowdhury, S., and Sikdar, S., (2016). Governance Performance of Indian States 200I-02 and 20II-I2,WP No. 164 (March)

- Mundle, S., Chakraborty, P., Chowdhury, S., and Sikdar, S., (2012). The Quality of Governance: How Have Indian States Performed?WP No. I04 (July)
Sudipto Mundle, is Emeritus Professor, NIPFP

Email: sudipto.mundle@nipfp. org.in

\section{MORE IN THE SERIES}

- Mundle, S. (2017). Beyond Catch Up: Some Speculations About the Next Twenty Five, WP No. 187 (January)

- Chhibber, A. and Gupta S., (2017). Public Sector Undertakings - Bharat's Other Ratnas, WP No. 186 (January).

- Ranjan, P. R. (2016). Indian Variant of MTEF: The Scope and Opportunities to Develop an Effective Budget Planning Process, WP No. 185 (December)

National Institute of Public Finance and Policy,

18/2, Satsang Vihar Marg, Special Institutional Area (Near JNU),

New Delhi I 10067

Tel. No. 26569303, 26569780, 26569784

Fax: 9 I- I I-26852548

www.nipfp.org.in 